\title{
Party Cues in the News: Democratic Elites, Republican Backlash and the Dynamics of Climate Skepticism ${ }^{1}$
}

\author{
Eric Merkley \\ Postdoctoral Fellow \\ Munk School of Global Affairs \& Public Policy \\ University of Toronto \\ eric.merkley@utoronto.ca \\ Dominik A. Stecula \\ Postdoctoral Fellow \\ Annenberg Public Policy Center \\ University of Pennsylvania \& \\ Simon Fraser University \\ dominik.stecula@appc.penn.edu \\ ***Forthcoming in the British Journal of Political Science***
}

\begin{abstract}
Supporters of the Republican Party have become much more skeptical of the science of climate change since the 1990s. We argue that backlash to out-group cues from Democratic elites played an important role in this process. We construct aggregate measures of climate skepticism from nearly 200 public opinion polls at the quarterly level from 2001 to 2014 and at the annual level from 1986 to 2014. We also build time series measures of possible contributors to climate skepticism using an automated media content analysis. Our analyses provide evidence that cues from party elites especially from Democrats - are associated with aggregate dynamics in climate change skepticism including among supporters of the Republican Party. We then conduct a party cue survey experiment on a sample of 3,000 Americans through Amazon Mechanical Turk to provide more evidence of causality. Together, these results draw attention to the importance of out-group cuetaking and suggest we should see climate change skepticism through the lens of elite-led opinion formation.
\end{abstract}

\footnotetext{
${ }^{1}$ We would like to thank Paul Quirk, Richard Johnston, Fred Cutler, Stuart Soroka, Chris Wlezien, Josh Pasek, Brendan Nyhan, Philip Habel, Yphtach Lelkes, and members of the UBC ComparativeCanadian Workshop for helpful feedback at various stages of the project. Thanks also to Mark Warren and Spencer McKay for generously including our questions as part of their larger survey for an unrelated project. Our doctoral research was funded by the Social Science and Humanities Research Council of Canada [grant \# 767-2015-2504 and 752-2015-2536] and the survey experiment was approved by the UBC Behavioural Research Ethics Board [protocol \# H19-00311].
} 
American public opinion is highly polarized on climate change. Surveys show that an overwhelming majority of Democrats believe climate change is happening, while that same belief among Republicans is more limited, especially for the most conservative supporters of the GOP (Tesler 2017). This polarization mirrors where Democratic and Republican elites stand on the issue. But it was not always this way. Republicans once had beliefs about climate science comparable to Democrats. For example, in 1997 the gap between strong partisans on whether global warming was real was only 5 percentage points, with 73 percent of Democrats and 68 percent of Republicans believing that global warming was happening (Krosnick et al. 2000). Why exactly did an increasing number of Republicans come to reject the climate science consensus?

We argue that climate skepticism among Republicans may have been encouraged by polarizing party cues communicated through the news media, and specifically those from Democratic elites the out-group party that has dominated climate change news coverage and has sent consistent signals to the mass public in support of the scientific consensus. This top-down model of attitude formation has a rich history in public opinion scholarship (see Berinsky 2009; Lenz 2012; Zaller 1992), but research is comparably more limited on the importance of out-group cues in causing attitudinal backlash among partisans (but see Bischof and Wagner 2019; Feddersen and Adams 2018; Goren et al. 2009; Nicholson 2012 for recent, important exceptions).

Moreover, the role of party elites writ large has been underexplored in literature on climate change politics that is primarily focused on ideology-driven motivated cognition (Campbell and Kay 2014; Dixon et al. 2017; Kahan et al. 2011), organized climate skeptics and the journalistic practice of false balance (Boykoff and Boykoff 2007; Dunlap and McCright 2011; Dunlap and Jacques 2013), and economic costs and related media framing (Nisbett 2009; Scruggs and Benegal 2012). Some scholars have recently begun to explore the role of party elite cues in the context of climate change (Carmichael and Brulle 2017; Guber 2013; Tesler 2017), but these works do not distinguish between in-group and out-group cueing and do not analyze the news media, which play a critical role in communicating elite cues to the mass public.

In this paper, we build novel measures of aggregate climate change skepticism annually starting in 1986 and quarterly starting in 2001. We use a combination of dictionaries and supervised machine learning to identify news articles with party elite cues and common climate change news frames that are likely to be correlated with such signals. We find that Democratic elite cues lead, rather than follow, aggregate levels of climate skepticism and skepticism among Republican identifiers. We also demonstrate that these cues are correlated with our aggregate public opinion 
measures when controlling for confounders, such as the dynamics of cues from Republicans and common news media frames like the economic cost of climate change mitigation and scientific uncertainty. For stronger causal identification, we conduct a survey experiment on a sample of almost 3,000 American citizens and find that exposure to Democratic elite cues is associated with higher levels of self-reported climate skepticism among Republicans. The backlash effect found here is similar in size to providing Republicans in-group cues from Republican elites, but, importantly, its effect can be attenuated by a consensus cue in which Democratic and Republican elites signal agreement on climate science and mitigation.

In short, this paper uniquely combines text analysis, time series modelling, and experiments to illustrate the power of out-group cues in a real world setting on an issue of high salience, and, in the process provides a compelling explanation for the otherwise perplexing polarization of Americans on an important area of scientific consensus.

\section{Party Elites and Climate Skepticism}

Republican Party supporters are now much more skeptical of climate science than they were in the 1990s. Some scholars have highlighted ideology and values as the root cause of this phenomenon. These theories draw strongly from psychological research on motivated reasoning (Ditto and Lopez 1992; Kunda 1990). Citizens may be motivated to resist messages from experts or seek out information from contrarian sources in support for their values and identities (Kahan et al. 2011; Leiserowitz 2006; Lewandowsky and Oberauer 2016; Pasek 2017). And, in this case, the policy implications of climate change are not easily compatible with free market orthodoxy (Campbell and Kay 2014; Dixon et al. 2017; Oreskes and Conway 2010). In this view, we are very unlikely to change people's minds unless we can reconcile climate action with these value predispositions.

However, there are important limitations to this approach. First, most Americans do not harbour consistent ideological predispositions (Achen and Bartels 2016; Kinder and Kalmoe 2017). This fact becomes apparent in the climate change context where market-friendly ways to reduce carbon emissions, like carbon pricing, are much less popular among Republicans even with revenue recycling (Amdur et al. 2014). Most people who label themselves as conservatives do not take consistent conservative positions on fiscal issues (Barber and Pope 2017; Drutman 2017). More importantly for our purposes here, explanations rooted in motivated reasoning do not easily account for dynamics - conservatives and Republicans once had very similar views on climate change as liberals and Democrats (Krosnick et al. 2000). And it is the dynamics that interest us most here. 
We believe considerable light is shed on this question by a long line of work in political science that has shown the importance of top-down persuasion by party elites in opinion formation. This occurs because many people use cues from parties as cognitive short cuts to make decisions in a low information context (Cohen 2003; Conover and Feldman 1989; Kam 2005; Lenz 2012; Popkin 1991) or form opinions in line with their strong affect-oriented attachments to parties (Lodge and Taber 2013). As a result, party elites can have considerable persuasive power (Cohen 2003; Kam 2005).

Most research on party cues focus on in-group cues, where partisans are responsive to signals from their own party's elites either because of the informative value of such cues or because of their own affective attachment to their party's leaders. However, partisans may also be responsive to outgroup cues where they are repelled by signals from the opposing party's elites, rather than being persuaded. Again, the mechanism undergirding such responsiveness could be either a rational process of learning in a low information context or a social-psychological response to negative affect associated with out-group elites. The latter of which has increased in importance over time as partisans have become affectively polarized (Iyengar et al. 2012).

Some empirical work has shown that out-group cues can cause "backlash" in the United States. In an experimental setting, Nicholson (2012) manipulates the existence of cues from, at the time, presidential candidates John McCain and Barack Obama, as well as President George W. Bush, on a pair of bills related to immigration and foreclosure. He finds that out-group cues repelled partisans more than in-group cues persuaded co-partisans. Goren and his colleagues (2009) likewise find that party elites cues can influence the degree to which partisans agree with value statements, with out-group party cues being notably more powerful. Observationally, it is tricky to disentangle the effects of in-group and out-group cues since they typically rise and fall together with issue salience in the real world. Berinsky (2009), however, shows that Democratic identifiers turned against support for the Iraq War even when the signals sent by their own party's elites were mixed, suggesting the responsiveness of these partisans to unified Republican elite support.

There is also some evidence of out-group cueing in the comparative context. Bischof and Wagner (2019) find that the entry of ideologically extreme parties into Dutch parliament had a polarizing effect on citizens. Specifically, the entry of far-right parties pushed left-wing partisans further to the ideological left. Similarly, Feddersen and Adams (2018) show that Swiss voters were influenced by party positions on migration as signalled by press releases - including notable backlash 
to out-group parties. There is a growing sense that out-group cues may be as important as in-group cues in opinion formation, and perhaps even more so.

There are grounds to expect that party cues may have played an important role in stimulating climate skepticism. Most Americans get their information on climate change primarily from the news media (Tesler 2017), which has increasingly carried party cues to the public as the issue rose in salience (Merkley and Stecula 2018). Importantly, these elite cues signal the existence of a sharp political divide to the public, unlike in other countries (McCright and Dunlap 2011). Party elite cues certainly had the opportunity to shape American attitudes on climate change, but that is far from evidence they may have been responsible for over time dynamics in climate skepticism.

Observational evidence has been consistent with the predictions of elite cueing theory. First, the sharpest divide on climate science exists among those who are high in education, those who consume the most news, and those who are most attentive to the issue (Guber 2013; Tesler 2017), which is in line with Zaller (1992). Importantly, elite cueing theory also passes a placebo test - this finding does not hold in other countries where party elites are not as divided on climate action (Tesler 2017). Second, research has found that concern about climate change is correlated with legislative activity, like committee hearings (Carmichael and Brulle 2017). Finally, there is some experimental evidence that softening Republican elite positions on climate change changes Republican attitudes towards climate science (Tesler 2017).

That being said, these works have some notable limitations. First, they do not build the news media environment into their analysis even though it plays an important role in this process by communicating elite cues to the broader public (Althaus et al. 1996; Bennett 1990; Dalton et al. 1998). Second, and more importantly for our purposes here, these works cannot distinguish between out-group and in-group cueing effects. And there is reason to suspect out-group cues may have played a particularly important role in shaping evolving Republican attitudes towards climate change. Democratic cues are much more pronounced in climate coverage and Republican cues had been inconsistent in their direction - either in support or in opposition to climate action - at least until 2009 (Merkley and Stecula 2018). It is a case that, in some respects, resembles elite debate surrounding the Iraq War, where in-group party cues from Democratic elites were muddled and not particularly informative compared to out-group party cues from Republicans for Democratic partisans (Berinsky 2009).

The clear observable implication is that there should be some association between the prevalence of cues from Democratic elites in the news media - where most Americans learn about 
climate change - and climate skepticism. However, one complication in interpreting over time correlations on this question is the threat of reverse causality. A sizable literature in opinion formation tells us that elites are often an important influence on public attitudes (Lenz 2012; Zaller 1992), but policymakers are often responsive to public opinion for the purposes of securing reelection (Erikson et al. 2002). As a result, we expect to see that Democratic elite cues lead, rather than follow aggregate levels of climate skepticism.

H1: The prevalence of Democratic Party elite cues in the news lead aggregate levels of skepticism towards climate science.

The above hypothesis is tested with vector autoregression (VAR). More will be said on this below, but one limitation of this approach is that it does not speak to contemporaneous relationships between variables. For more evidence of a causal process, we want to also show that there is positive, contemporaneous association between these variables, holding constant other factors we might think are important.

One source of confounds are other dynamics found in political discourse. The most obvious candidate as a confounder are cues from Republican elites. Journalists often cite "both sides" in a story to preserve balance (Boykoff and Boykoff 2007). As a result, Republicans are likely to be cited, alongside Democrats, in periods where climate change and related policy are salient. Republican supporters are also likely to take cues from their in-group party on climate change, so we need to control for them.

Additionally, we want to account for frames in discourse that might influence climate skepticism, while also being correlated with the prevalence of party elite cues. This is because party elites use such frames when justifying the stances they take in news coverage of climate change. Frames that emphasize the economic costs of climate mitigation or scientific uncertainty might be of particular importance in explaining climate skepticism. We know that poor economic conditions (Brulle et al. 2012; Carmichael and Brulle 2017; Elliott et al. 1997; Scruggs and Benegal 2012), energy prices (Scruggs and Benegal 2012), and the cost of reforms reduce support for policy action (Ansolabehere and Konisky 2014; Bechtel and Scheve 2013). In light of this, opponents of climate change action use frames related to economic cost, which is carried to the mass public by the media (Nisbet 2009). Over the course of a policy debate where costs and benefits are debated these frames 
appear with some regularity (Stecula and Merkley 2019), and experimental evidence has shown that these frames can move public opinion (Davis 1995; Vries et al. 2016).

Other analysts have highlighted a campaign orchestrated by industry and conservative movement groups to highlight supposed uncertainties in the fundamental tenets of the consensus of the Intergovernmental Panel on Climate Change (IPCC) - that climate change is happening, manmade, and a serious threat (Dunlap and Jacques 2013; Farrell 2016a, 2016b; Jacques et al. 2008). They engaged in this framing in order to reify the status quo (Feyinga et al. 2010). Journalists, for their part, unwittingly elevated these arguments to provide balanced coverage (Boykoff and Boykoff 2007; Dunlap and McCright 2011). Content analyses have shown that uncertainty framing has been prevalent in the past (Boykoff and Boykoff 2007; Painter 2012; Painter and Ashe 2012), and there is some experimental research that the citation of contrarian experts does indeed confuse the public on the state of science (Corbett and Durfee 2004; Friedman et al. 1999; Koehler 2016).

These frames may influence public attitudes towards climate change. These are also frames that are likely to be used by Republican elites in the course of a political debate. To the extent that dynamics in these frames are correlated with party elite cues, they may serve as confounds, which leads to our second hypothesis:

H2: There is a positive, contemporaneous correlation between the prevalence of Democratic Party elite cues and climate skepticism, holding other factors constant.

Showing evidence of a correlation between Democratic elite cues and aggregate climate skepticism in which the former has temporal precedence and where the relationship is robust to controls would provide some evidence of out-group cueing effects on climate skepticism, but ultimately such a design is not causal. A large experimental literature has shown party cues can influence attitudes on a number of questions related to public policy, but most of this work focused on in-group cues and almost none has used climate change as a test case. Experimental evidence in support of an out-group cueing effect on attitudes towards climate science would help shore up our causal claim:

H3: Skepticism of climate science will be higher among Republicans when respondents are exposed to a cue signaling the support of the Democratic Party to climate science and mitigation. 


\section{Aggregate Time Series Data and Methods}

We begin by outlining the method and results for our aggregate time series analyses before moving on to the design and results of our experiment. We follow the lead of Stimson (1999) in measuring aggregate levels of climate change skepticism. We combine 172 different poll questions since the late 1980s from the Roper Center archive at Cornell University, which is a repository of a wide selection of polls addressing climate change attitudes.

The questions we use for our measure include those that asked respondents whether or not climate change is happening, whether or not climate change is a serious problem, whether or not they are worried about global warming, and whether or not climate change is caused by humans. ${ }^{2}$ After ensuring all of the questions were coded in the same direction, we used them to extract a latent measure of public skepticism of climate change. We are able to construct an annual measure beginning in 1986 and a quarterly measure starting in 2001 with available polling data. Our aggregate climate skepticism measures are presented in the left and center panels of Figure 1.
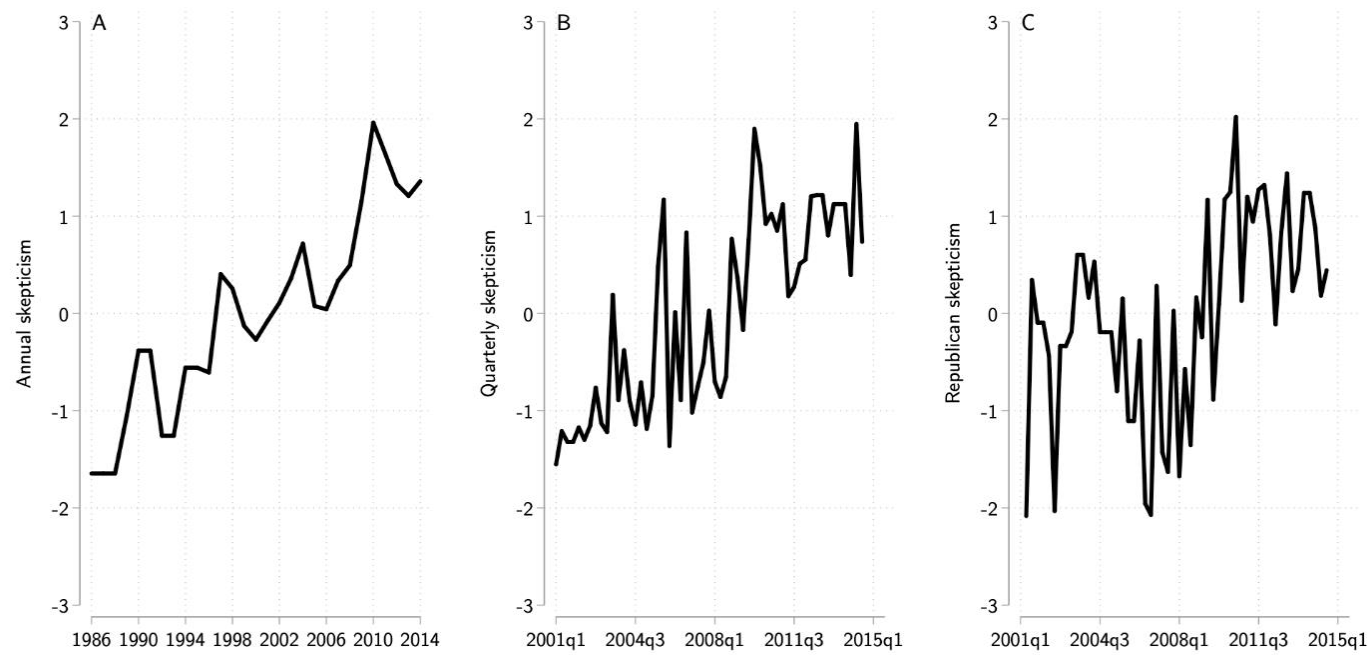

Figure 1. Climate Change Skepticism. A) Annual, 1986-2014, B) Quarterly, 2001-2014, C) Republicans, Quarterly, 2001-2014. Note: all series displayed without WCalc smoothing.

\footnotetext{
${ }^{2}$ The data presented in the paper is based on the broadest set of questions that we found, coupled with the questions shared by Carmichael, Brulle, and Huxster. This measure excludes outliers, though they do not substantively change the results. More information on the mood measure can be found in section A of the supplementary information.
} 
The aggregate measures of climate skepticism used here, however, do not tell us what is happening specifically with Republican identifiers. Carmichael and Brulle (2017) constructed a quarterly measure for Republicans starting in 2001 using the same method. Their Partisan Climate Change Threat Index (PCCTI) uses a slightly different subset of climate change polling questions focused exclusively on perceptions of the seriousness of the threat posed by climate change. The series for Republican identifiers is presented in panel $\mathrm{C}$ of Figure 1 reverse-coded so that higher values indicate more skepticism of climate change. Our quarterly variant of aggregate climate skepticism is highly correlated with the reverse-coded Republican PCCTI (0.48). We standardize our public opinion measures for ease of interpretability.

The dynamics of aggregate opinion on climate science are likely explained in part by changes in the news media information environment. As a result, our primary variables of interest are constructed from a media content analysis. We downloaded climate change coverage of the New York Times and the Washington Post from LexisNexis. We chose these sources for a number of reasons. First, newspapers play a more important role in informing the electorate than television (Druckman 2005) and these are two of the highest circulation newspapers in the United States that are traditionally seen as agenda-setting outlets throughout our period of study (Golan 2007; McCombs 2005). ${ }^{3}$ As a result, numerous studies in the field of political communication use these sources as proxies for the news media (see, for example: Eyck and Williment 2003; Farnsworth and Lichter 2005, Soroka et al. 2015). Second, we needed sources that were continuously available since the beginning of the time period of our study in 1986, which ruled out sources like the USA Today or the Wall Street Journal. Articles and transcripts were selected if they mentioned climate change or global warming in the body of the text or the subject tag. We then ensured the articles were relevant and primarily focused on climate change. ${ }^{4}$

\footnotetext{
${ }^{3}$ We acknowledge that the agenda-setting power of these traditional news outlets might have dissipated recently with the growth of partisan online media (see Vargo and Guo 2017), but we are mostly concerned with developments that occurred before online and social media have grown in prominence.

${ }^{4}$ We accomplished that by hand coding over 1000 articles for relevance and then using ensemblebased supervised machine learning with the RTextTools package to purge our sample of irrelevant articles.
} 
Our definition of a party cue in this context is an explicit or implicit stance on climate change science or related policy attributed to elites of either the Democratic or Republican Party. We measure these cues using the automated content analysis software Lexicoder in conjunction with a dictionary of key terms, such as party names, office titles and party leaders. These leadership positions include presidents, presidential nominees, vice presidents, Speakers of the House, and Senate and House majority and minority leaders. Our dictionaries can be found in section B of the supplementary information. We classify articles for whether or not they have reference to the Democratic or Republican Party and their respective elites. Of course, not all articles with party references contain cues signaling elite positions on climate change, but the overwhelming majority of them do. We manually coded a random sample of 700 articles that had a reference to either party in the text to validate our automated measure. Approximately $80 \%$ of these articles contained what could be considered a cue on climate change by our definition.

We constructed a time series measure of the share of articles in a given period that contain cues from Democratic and Republican elites, respectively. We use shares because volume measures are more likely to be correlated with other factors that are also associated with the overall salience of climate change. However, our results are robust to using measures of the volume of articles with party cues as shown in Table D1 of the supplementary materials.

One limitation of using these measures is that they do not account for the message being conveyed by party elites. We manually coded a random sample of 3000 news articles and transcripts on climate change that an identical automated analysis indicated featured either Democratic and Republican cues for a related project. We scored articles for whether they contained a consistent message from a party either in favour or opposed to the climate consensus, or if the messages in the article were mixed in their orientation. ${ }^{5}$ The overwhelming majority $(97 \%)$ of articles featuring messages from Democratic elites contained messages that were entirely supportive of the climate consensus, even as far back as the 1980s. In contrast, Republican elites oscillated between periods of strident opposition to the climate consensus, such as during the Kyoto debate, and conciliatory

\footnotetext{
${ }^{5}$ We trained an undergraduate coder to replicate our coding on a sample of 300 articles with Democratic or Republican cues, respectively. There was high agreement between our coding and that of our undergraduate research assistant with Krippendorf's alpha scores of 0.98 for Democratic messages and 0.83 for Republican messages.
} 
messages during the later stages of the Bush administration. Notably, our coding of the share of Republican messages hostile to climate science and mitigation is highly correlated with the League of Conservation Voters congressional roll call score on the environment for Republicans in the House and Senate (0.72), suggesting it is a valid indicator of the stance taken by Republican elites on climate change.

Consequently, we multiply the proportion of climate news stories with Republican cues by the proportion of Republican messages uniformly hostile to climate science or mitigation. This gives us an estimate of the share of climate news stories with Republican cues with this specific message. We show the comparison between the share of news stories with Republican cues, our hand coding, and our composite measure in Figure C1 of the supplementary materials. We use this composite measure in the analyses that follow.
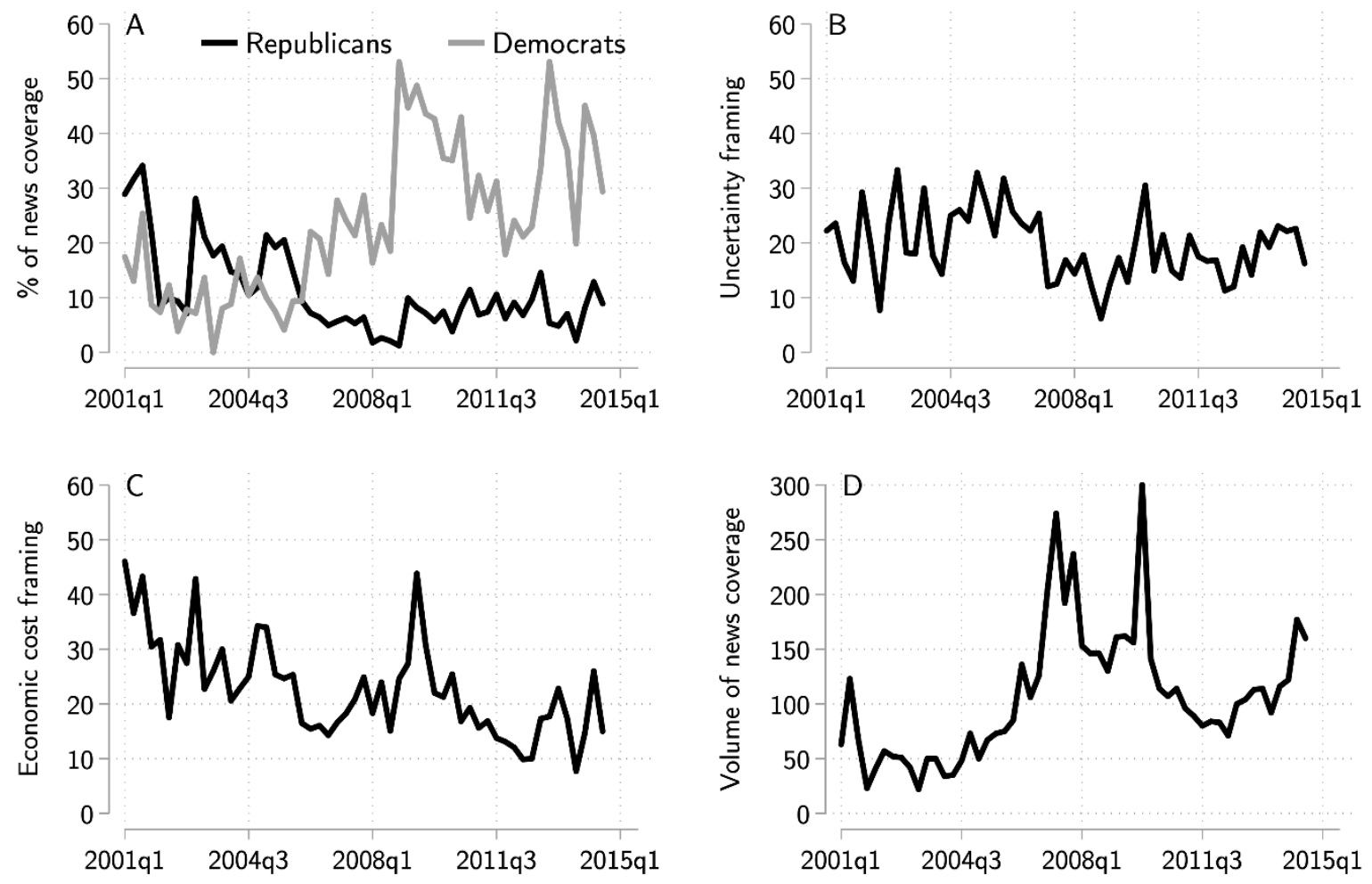

Figure 2. Potential Polarizers in the News, Quarterly Data 2001-2014. A) Democratic, and Republican cues in news coverage; B) Uncertainty framing; C) Economic cost framing; D) Salience of coverage.

Our quarterly measures for Democratic and Republican cues are displayed in panel A of Figure 2. The panel shows that Democratic cues have had a sustained increase since 2008, while 
Republican cues with messages hostile to climate science and mitigation have been on the decline since 2001. An annual version of this graph starting in 1986 can be found in panel A of Figure C2 of the supplementary materials.

\section{$\underline{\text { Models }}$}

The first set of hypotheses address the direction of the association between party cues and aggregate climate skepticism. We can shed some light on this by estimating a reduced form vector autoregression (VAR) where our endogenous variables are regressed on their past values and the past values of the other endogenous variables in our system. The downside of this approach is that it does not tell us anything about the contemporaneous relationships between the variables. We cannot use the results to infer causality. We can, however, learn whether one variable "granger causes" another - that is, do past values of a variable facilitate the prediction of current values of another variable above and beyond the previous values of other variables in the system.

We estimates a series of VAR equations to disentangle the relationship between aggregate climate skepticism and party elite cues. ${ }^{6}$ We control for exogenous changes in the climate, comprised of a standardized index by the NOAA of the share of days below the average temperature or in drought conditions. We also hold constant exogenous dynamics in economic conditions, proxied with unemployment rates and crude oil prices taken from the Federal Reserve's FRED database. Finally, we control for seasonality with dummies representing the quarter of the year. We do not control for a linear trend because we do not think it is theoretically defensible. Ultimately, we are interested in accounting for any trends in public attitudes towards climate change. Here we display the results of granger causality tests. We expect Democratic elite cues to granger cause aggregate climate skepticism, but not the reverse (H1). Republican cues are also likely to lead aggregate climate skepticism, though this is less central for our purposes here.

\footnotetext{
${ }^{6} \mathrm{VAR}$ estimates are somewhat sensitive to the chosen lag lengths, particularly with $\mathrm{T}$ in the small to intermediate range. Theoretically, we do not expect our variables to cause other variables past a lag length of four quarters, or a year. There are a number of different methods to choose the appropriate lag length. In cases of disagreement between the tests on the appropriate lag length, the higher lag length was chosen. All characteristic roots lie inside the unit circle, meeting the stability condition for a stationary VAR system.
} 
To test our second hypothesis, we estimate lagged dependent variable models quarterly from 2001 to 2014 and annually from 1986 to 2014 that regress aggregate climate skepticism on its lag, Democratic elite cues, and a set of controls. We have theoretical reason to expect memory in our dependent variable - climate skepticism at $\mathrm{t}-1$ is likely to partially cause its value at $\mathrm{t}$ because there tends to be stickiness in public opinion - so omitting the lag could lead to biased estimates. More formally, the model is represented in equation 1. $\beta_{1}$ should be positive and significant to provide support for $\mathrm{H} 2$.

climate skepticism $_{t}=\alpha+\delta$ climate skepticism $_{t-1}+\beta_{1}$ democratic cues $_{t}+\beta_{2-11} X+\varepsilon$

$\mathrm{X}$ in the above equation represents a series of media and non-media controls. First, we expect there so be some correlation between Republican and Democratic elite cues, and the former may also be correlated with aggregate climate skepticism because of an in-group cueing process. Second, we have some expectation that frames related to uncertainty and economic cost may be both associated with the prevalence of party elite cues and climate attitudes. Emphasis frames can be less adequately captured with simple dictionaries. As a result we identified stories with economic cost and uncertainty frames by using supervised machine learning, which is increasingly used to study news content and political discourse more broadly (Grimmer and Stewart, 2013, Lacy et al., 2015).

We manually coded a random sample of 2,179 newspaper articles stratified across three periods (1980-1996, 1997-2005, and 2006-2014) to minimize any fluctuation in the performance of the algorithm as climate change rose in salience. Articles and transcripts were coded as " 1 " if they have discussion of perceived costs of climate change mitigation, such as higher energy prices, a weaker economy, fewer jobs, declining competitiveness against developing countries, and costs of regulatory compliance. These articles contained economic cost frames. On a separate dimension they were coded " 1 " if they had any discussion questioning the major elements of the IPCC consensus that climate change is happening, predominantly man-made, and a serious threat. ${ }^{7}$ These articles $^{2}$ contained uncertainty frames.

\footnotetext{
${ }^{7}$ One researcher completed the hand coding of the full set. The second researcher randomly selected $10 \%$ of these articles (200 articles) to validate the coding. Our Krippendorf's Alpha score is 0.88 for uncertainty frames ( $96 \%$ agreement), and 0.87 for economic cost frames ( $95 \%$ agreement). Our manual coding input is highly reliable.
} 
We trained a pair of Support Vector Machine (SVM) algorithms on our manually coded articles. ${ }^{8}$ SVM is a supervised machine learning technique that plots data points on an $\mathrm{n}$-dimensional space to find a hyperplane that best differentiates different classes of objects. We randomly divided our manually coded set into a training $(80 \%)$ and testing set $(20 \%)$ for each coding task to validate our automated classification. We found reasonably close agreement between our classifier and our manual coding. Importantly, the prevalence of false positives and false negatives are similar, meaning our estimates of the prevalence of these frames are likely unbiased over a large number of observations in each period. ${ }^{9}$

Panel B of Figure 1 displays the prevalence of uncertainty frames at the quarterly level since 2001. They have declined from around 20 to $25 \%$ before 2007 to $15 \%$ afterward. The annual variant of this graph in panel B of Figure C2 shows more clearly that uncertainty frames have been on the decline since a peak of around $45 \%$ in 1997. Panel C illustrates the dynamics of economic cost frames. They too have been on the decline since 2001. The annual variant in panel C of Figure C2 shows that they tend to increase in times of policy debate, like in 1992, 1997, and 2001.

As expected, the prevalence of Republican cues are correlated with economic cost frames quarterly (0.64) and annually (0.55), but interestingly not as strongly with the prevalence of uncertainty frames $(0.34 \&-0.07)$. Nevertheless, controlling for the dynamics in these frames will give us more confidence that we are seeing evidence of a causal association between party elite cues and climate skepticism. Second, we control for salience with the combined number of stories in the New York Times and the Washington Post on climate change. The volume of articles is plotted in panel D of Figure 2. Salience steadily increased going into 2007, and spiked again in 2009 and 2010. There appears to have been a sustained increase in the equilibrium level of climate change salience. The annual variant of this plot can be found in panel D of Figure C2 in the supplementary materials. The

\footnotetext{
${ }^{8}$ We randomly removed articles from the manually coded set classified as " 0 " for each coding task in order to ensure those classified as " 1 " represented at least a third of the manually coded set. We found algorithm performance could be optimized by providing more balance between classes in the training set. This resulted in a combined hand coded set of 1,878 articles for economic cost frames, and 1,179 articles for uncertainty frames.

${ }^{9}$ Our cost frame classifier was $80 \%$ accurate with average recall and precision scores of 0.76 and 0.80 , respectively. Our uncertainty frame classifier was $77 \%$ accurate with average recall and precision scores of 0.70 and 0.68 , respectively.
} 
prevalence of Democratic cues is highly correlated with climate change salience quarterly (0.57) and annually (0.57), however, this is not true with Republican cues $(-0.45 \& 0.11)$. Finally, we preserve our controls for climate and economic conditions, and seasonality from the VAR models.

\section{Aggregate Time Series Results}

Displayed in Table 1 are the results of granger causality tests. The top panel shows our tests using quarterly aggregate climate skepticism, while the bottom panel uses our measure of climate skepticism for Republican identifiers. There is strong evidence that Democratic cues lead climate skepticism (H1). These signals in the news media granger cause aggregate climate skepticism ( $p \sim 0.01)$ and climate skepticism specifically among Republican identifiers ( $p \sim 0.03$ ), while climate skepticism does not granger cause these cues ( $\mathrm{p} \sim 0.32 \& \mathrm{p} \sim 0.86)$. In contrast, there is only weak and inconsistent evidence of an in-group cue-taking process. Republican cues do not granger cause overall aggregate levels of climate skepticism ( $\mathrm{p} \sim 0.94)$, but they do weakly granger cause skepticism for Republicans specifically ( $\mathrm{p} \sim 0.09)$. Climate skepticism does not granger cause Republican cues in either case $(\mathrm{p} \sim 0.82 \& \mathrm{p} \sim 0.99)$.

The VAR analyses provide some evidence of a cue-taking on climate change, with a comparatively stronger sign of out-group cue-taking among Republicans. Democratic elite cues appear to lead Republican climate skepticism, signaling that these citizens have been repelled by Democratic messages on climate change (H1).

Table 1. Granger Causality Tests

\begin{tabular}{llll}
\hline \# of Lags & Granger Causality Tests & chi2 & p-value \\
\hline \multirow{2}{*}{1} & Democratic Cues $\rightarrow$ Climate Skepticism & 6.96 & 0.01 \\
& Climate Skepticism $\rightarrow$ Democratic Cues & 1.01 & 0.32 \\
& GOP Cues $\rightarrow$ Climate Skepticism & 0.00 & 0.94 \\
\hline 2 & Climate Skepticism $\rightarrow$ GOP Cues & 0.05 & 0.82 \\
\hline \multirow{2}{*}{1} & Democratic Cues $\rightarrow$ GOP Climate Skepticism & 7.35 & 0.03 \\
& GOP Climate Skepticism $\rightarrow$ Democratic Cues & 0.29 & 0.86 \\
& GOP Cues $\rightarrow$ GOP Climate Skepticism & 2.94 & 0.09 \\
& GOP Climate Skepticism $\rightarrow$ GOP Cues & 0.00 & 0.99 \\
\hline
\end{tabular}


One limitation of the previous analyses is that they do not provide evidence of contemporaneous relationships. We might also want to tease out whether it is the dynamics in Democratic elite cues that are affecting opinion or other elements of media discourse doing the work that are likely correlated with such cues. Table 2 provides our results for our contemporaneous models. Again, there is stronger evidence of out-group cue-taking (H2). Model 1 shows that A 10 percentage point increase in the share of Democratic cues in climate coverage is associated with a 0.2 standard deviation increase in climate skepticism ( $p \sim 0.07)$. Republican cues are non-significant. Aside from Democratic cues, unemployment also appears to be strongly correlated with aggregate climate skepticism $(\mathrm{p}<0.01)$.

Table 2. Predictors of Aggregate Climate Change Skepticism

\begin{tabular}{|c|c|c|c|}
\hline & \multicolumn{2}{|c|}{$\begin{array}{l}\text { Aggregate Climate } \\
\text { Skepticism }\end{array}$} & \multirow{3}{*}{$\begin{array}{l}\text { GOP Climate } \\
\text { Skepticism } \\
\text { Quarterly } \\
3\end{array}$} \\
\hline & Quarterly & Annually & \\
\hline & 1 & 2 & \\
\hline \multirow[t]{2}{*}{ Democratic Cues } & $0.02 *$ & $0.02 *$ & $0.03 * * *$ \\
\hline & $(0.01)$ & $(0.01)$ & $(0.01)$ \\
\hline \multirow[t]{2}{*}{ Republican Cues } & 0.02 & 0.01 & $0.04 * *$ \\
\hline & $(0.01)$ & $(0.01)$ & $(0.02)$ \\
\hline \multirow{2}{*}{ Uncertainty Frames } & -0.00 & 0.02 & 0.01 \\
\hline & $(0.01)$ & $(0.01)$ & $(0.02)$ \\
\hline \multirow[t]{2}{*}{ Cost Frames } & -0.02 & -0.00 & -0.02 \\
\hline & $(0.01)$ & $(0.02)$ & $(0.02)$ \\
\hline \multirow[t]{2}{*}{ Media Salience } & 0.00 & 0.00 & $-0.00 * *$ \\
\hline & $(0.00)$ & $(0.00)$ & $(0.01)$ \\
\hline \multirow[t]{2}{*}{ Climate Index } & -0.11 & $0.21 *$ & -0.06 \\
\hline & $(0.08)$ & $(0.11)$ & $(0.10)$ \\
\hline \multirow[t]{2}{*}{ Oil Prices } & 0.00 & -0.00 & 0.00 \\
\hline & $(0.01)$ & $(0.01)$ & $(0.00)$ \\
\hline \multirow[t]{2}{*}{ Unemployment Rate } & $0.23^{* * *}$ & 0.08 & $0.31 * * *$ \\
\hline & $(0.07)$ & $(0.06)$ & $(0.08)$ \\
\hline \multirow[t]{2}{*}{$\mathrm{DV}_{\mathrm{t}-1}$} & 0.06 & $0.65^{* * *}$ & -0.11 \\
\hline & $(0.17)$ & $(0.09)$ & $(0.14)$ \\
\hline Constant & $-2.43 * * *$ & $-1.31 * *$ & $-2.56 * * *$ \\
\hline $\mathrm{N}$ & 55 & 28 & 54 \\
\hline $\mathrm{R}^{2}$ & 0.72 & 0.89 & 0.60 \\
\hline
\end{tabular}

Robust standard errors in parentheses, ${ }^{*} \mathrm{p}<0.1{ }^{* *} \mathrm{p}<0.05^{* * *} \mathrm{p}<0.01$ 
Our quarterly model of aggregate climate skepticism is restricted to the period of 2001-2014 because of polling availability. The same result holds for our annual version of the series starting in 1986 (Model 2). A 10 percentage point increase in the prevalence of Democratic cues is associated with a 0.2 standard deviation increase in aggregate climate skepticism $(\mathrm{p} \sim 0.09)$. Republican cues are not significantly related to aggregate climate skepticism ( $\mathrm{p} \sim 0.60)$.

Model 3 provides some evidence of both in-group and out-group cue-taking (H2) using our measure of Republican skepticism towards climate change provided by the PCCTI. A 10 percentage point increase in Democratic cues is associated with a 0.3 standard deviation increase in Republican climate skepticism $(\mathrm{p}<0.01)$, while a 10 percentage point increase in Republican cues opposed to the climate change science or mitigation is associated with a 0.4 standard deviation increase in Republican climate skepticism ( $p \sim 0.02$ ). After controlling for party cue prevalence, uncertainty and economic cost framing is not associated with Republican climate skepticism. Republicans also appear responsive to the unemployment rate. A one point increase in the unemployment rate is associated with a 0.3 standard deviation increase in climate skepticism $(\mathrm{p}<0.001)$. Interestingly, Republicans become less skeptical of climate change when salience increases after controlling for the prevalence of party cues. An increase in 100 news articles per quarter about climate change is associated with a decrease of 0.4 standard deviations in Republican climate skepticism ( $\mathrm{p} \sim 0.03)$.

The previous results provide consistent support for an out-group cue-taking effect in climate change attitudes (H2). Democratic cues appear to be a key predictor of aggregate levels of climate change skepticism, as well as skepticism among Republicans specifically. Importantly, these cues lead, rather than follow, opinion (H1). Together these results suggest that Republicans are repelled, rather than persuaded by Democratic elite cues in climate change coverage. There is comparatively mixed evidence for in-group cue-taking.

\section{Experimental Design}

The previous section provides some observational evidence that Democratic elite cues lead aggregate levels of climate skepticism and are strongly associated with skepticism even after controlling for other elements of political discourse that might matter in shaping those dynamics. However, aggregate time series analyses only provide suggestive evidence of causality. There may be some other factors we have not measured over time acting as confounders.

For stronger evidence of a causal link between Democratic elite cues and climate skepticism, we conducted a survey experiment on a sample of almost 3,000 American respondents from 
Amazon Mechanical Turk (MTurk) in 2019. This sample is comparable to the American public in gender, race, partisanship, and ideology. But, it skews younger, wealthier, and more educated. A comparisons between our MTurk sample and the 2016 General Social Survey is shown in Table E1 in the supplementary information. This sample is comprised of people who are more likely to pay attention to climate change and to have well-formed opinions on the issue. Any treatment effects found in this sample are likely to be, if anything, a conservative estimate of the effect of elite cues on the American public.

Table 3. Party Cue Experimental Conditions

\begin{tabular}{lll}
\hline $\mathrm{N}=2970$ & No Democratic cue & Democratic cue \\
\hline No GOP cue & $\mathrm{N}=472$ (Control) & $\mathrm{N}=505$ (Democratic cue) \\
Opposing GOP cue & $\mathrm{N}=495$ (Opposing GOP cue) & $\mathrm{N}=493$ (Polarized cues) \\
Supporting GOP cue & $\mathrm{N}=534$ (Supporting GOP cue) & $\mathrm{N}=471$ (Consensus cues) \\
\hline
\end{tabular}

All respondents received a short statement outlining the scientific consensus on climate change. We randomly assigned respondents into one of two conditions to receive a cue about climate science and mitigation policy from Democratic elites. Respondents received no such cue in the control condition. We also want to compare the effects of receiving Democratic elite cues to receiving cues from Republican elites or from both, so we also randomly assigned respondents into three conditions to receive cues from Republican elites. One treatment condition signaled Republican opposition to climate science and mitigation policy, while another condition provided information that Republican elites were increasingly likely to support the scientific consensus and climate mitigation policy. Respondents in the control condition received no cue from Republican elites.

The experimental conditions are displayed in Table 3 and the text of the treatments can be found in the supplementary information. From these randomizations we can extract six distinct experimental conditions. The control condition does not contain a party cue of any sort. The Democratic cue condition contains only a cue from Democratic elites. The opposing Republican cue condition contains only a cue from Republican elites expressing skepticism in climate science and opposition to climate mitigation, while the polarized cues condition contains both this cue and the one from Democratic elites. The supporting Republican cue condition only contains a cue signaling 
increasing Republican acceptance of climate science and mitigation policy, while the consensus cues condition contains both this cue and a cue from Democratic elites.

The experimental protocol was as follows. Respondents first completed a short pre-treatment survey featuring questions related to their demographics and socio-economic status. They also indicated their partisanship and were given a pair of screener questions. ${ }^{10}$ Respondents were then exposed to the party cue corresponding to their treatment condition. They finally answered a question related to our dependent variable of interest - climate skepticism - by indicating their level of agreement with the following statement (Strongly agree to strongly disagree, 7 -point):

The Earth is getting warmer mostly because of human activity, such as burning fossil fuels

Fully $80 \%$ of respondents agree with the scientific consensus at some level, while only $13 \%$ disagreed to some degree. We re-scale this variable from 0 to 1 for the following analysis, where 1 indicates respondents who are the most skeptical of climate science. All descriptions of the variables can be found in Table E2 in the supplementary information.

Model

We estimate a simple model using OLS regression where we interact each of our treatment conditions with a measure of respondent partisanship on a 7-point scale ranging from strongly Democratic to strongly Republican. Partisanship, however, cannot be randomly assigned. Our treatment may have heterogeneous effects across other variables that are correlated with partisanship. One likely possibility is that the effect of our cue treatment may be moderated by the trust people have towards scientists - independent of partisan considerations - because each of our treatments involve parties either supporting or rejecting the scientific consensus illustrated in the control condition. The effectiveness of our treatment also likely varies across levels of political interest. We control for each of these variables and their interactions with our treatment conditions in our model with $\mathrm{X}$ representing our controls shown below in equation 2:

${ }^{10} 85 \%$ of respondents passed both screener questions. MTurk has increasingly - as of 2019 - faced challenges to data quality resulting from bots and those using VPNs to mask their international locations. We used a screening protocol to address this issue (see Winter et al., 2019). We also drop 130 respondents (4\%) who failed both screener questions. 
climate skepticism $=\alpha+\beta_{1}$ Democratic cue $+\beta_{2}$ opposing Republican cue $+\beta_{3}$ polarized cues + $\beta_{4}$ supporting Republican cue $+\beta_{5}$ consensus cues $+\beta_{6}$ PID $+\beta_{7}$ PID $*$ Democratic cue + $\beta_{8}$ PID $*$ opposing Republican cue $+\beta_{9}$ PID $*$ polarized cues $+\beta_{10}$ PID $*$ supporting Republican cue $+\beta_{11}$ PID $*$ consensus cues $+\mathrm{X}+\mathrm{X} * \beta$ Democratic cue $+\mathrm{X} * \beta$ opposing Republican cue + $+\mathrm{X} * \beta$ polarized cues $+\mathrm{X} * \beta$ supporting Republican cue $+\mathrm{X} * \beta$ consensus cues $+\varepsilon$

We expect positive, significant coefficients on $\beta_{7}$ and $\beta_{9}$ in support for $\mathrm{H} 3$, and we also expect a positive, significant coefficient on $\beta_{8}$ in line with in-group cue-taking.

\section{Experimental Results}

The estimated marginal effects from the model based on equation 2 are displayed below in Figure 3. The full estimation results can be found in Table E3 of the supplementary information. ${ }^{11}$ The results strongly support the findings of the aggregate time series analyses. Panel A shows the estimated effect of a Democratic Party cue on climate skepticism. The interaction term is positive and significant $(\mathrm{p} \sim 0.05)$. There is no significant effect on climate skepticism for those who are strongly Democratic, but among strong Republicans there is estimated to be an increase in climate skepticism of 0.06 points on the 0 to 1 climate skepticism scale - or about 0.2 standard deviations on that measure $(\mathrm{p} \sim 0.03)$. These results provide strong support for $\mathrm{H} 3$. The interaction for the opposing Republican cue treatment is also significant (Panel B; $\mathrm{p} \sim 0.02$ ). Again, there is no estimated effect of this treatment on strong Democrats, but among strong Republicans there is expected to be a similar 0.06 point increase on the climate skepticism index in response to the cue $(\mathrm{p} \sim 0.02)$. There is evidence here of both in-group and out-group cue-taking, primarily for Republican supporters.

\footnotetext{
${ }^{11}$ Table E3 also presents estimates of models without controls, and with the controls used here along with ideology. Ideology and partisanship are highly correlated in this sample (0.78), but nevertheless treatment effects for the Democratic and polarized cue conditions remain robust to including it as a control. Marginal effects are found in Figures E1 and E2 in the supplementary information. Table E4 shows the results are robust to including socio-economic and demographic controls such as education, income, race, gender, and age.
} 
Unsurprisingly, the treatment condition that contained both Democratic and opposing Republican cues also has a significant interaction (Panel C; $\mathrm{p} \sim 0.003$ ). There is expected to be a modest treatment effect among strong Democrats in the expected direction of 0.04 points, but it is only marginally significant ( $\mathrm{p}$ 0.09). Strong Republicans, however, are expected to increase their skepticism towards climate change by 0.09 points or 0.3 standard deviations on this measure ( $p \sim 0.002)$. These effects are stronger than those of the Democratic cue and opposing Republican cue conditions, but the interaction term is not significantly different from either. In contrast, neither the supporting Republican cue nor the consensus cue treatment conditions exerted a polarizing effect on respondents. The effect of Democratic cues on Republican climate skepticism appears to have been attenuated by the Republican elite cue supportive of the climate change consensus.
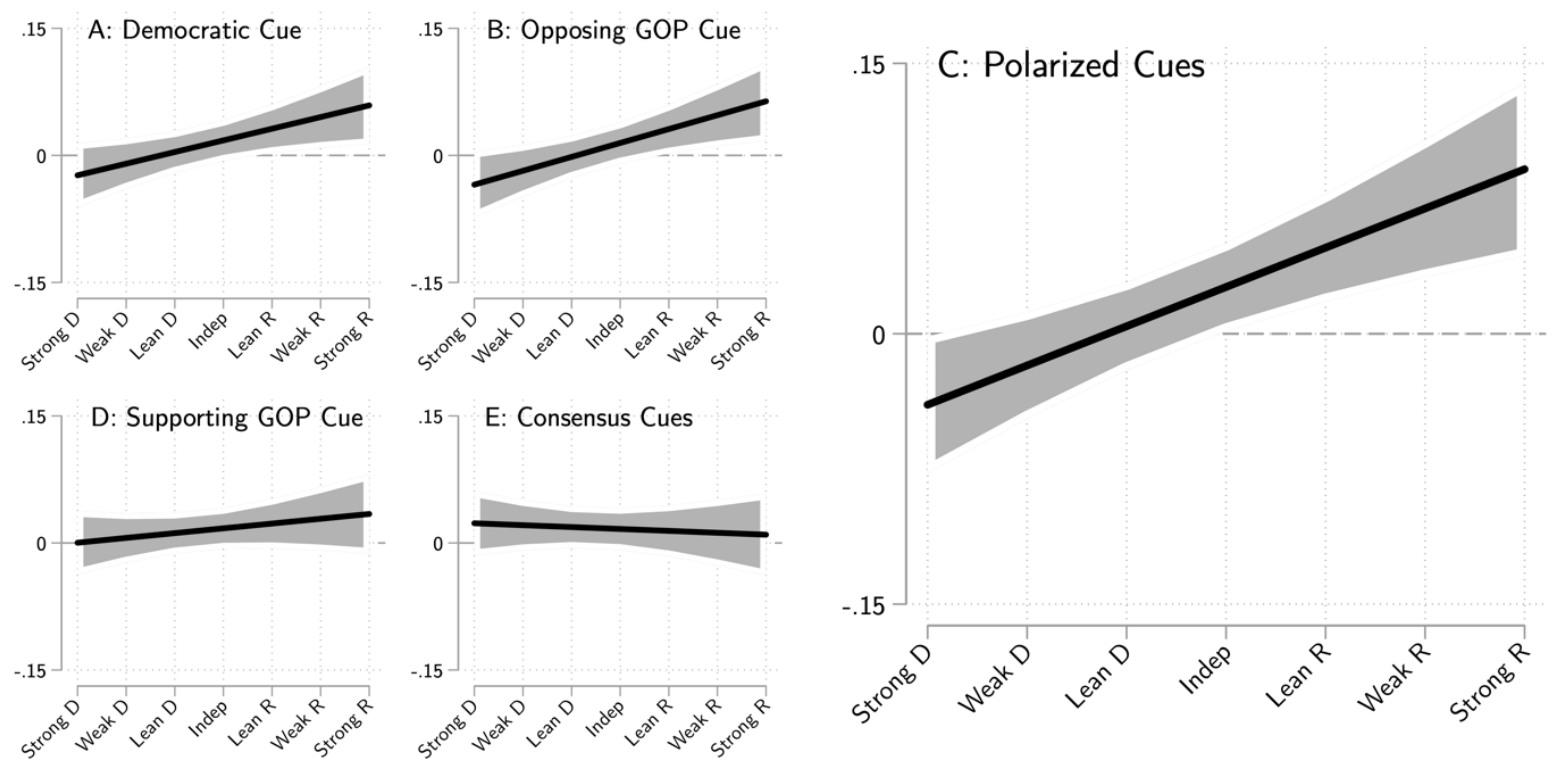

Figure 3. Estimated Effect of Party Cue Treatments on Climate Change Skepticism. (A) Democratic cue treatment; (B) Opposition Republican cue treatment; (C) Supportive Republican cue treatment; (D) Consensus cue treatments; (E) Polarized cue treatment. Note: 90\% confidence intervals.

In short, the experimental results presented here support the main findings from the aggregate time series analyses presented in the previous section. Republican respondents were responsive to out-group party cues from Democratic elites in their reported attitudes towards climate science. These effects are modest, but they are still remarkable given decades of partisan polarization that has already occurred on this question and the relatively thin nature of the treatments used here. 


\section{Discussion}

Climate scientists, politicians, and political scientists alike have been perplexed that a sizable portion of the American public rejects climate science, particularly among Republican Party supporters. Some have pointed to the role of organized climate denialists and the prevalence of 'false balance' in news coverage, others have highlighted the importance of ideology and media framing. Taking a back seat until recently has been the role of party elites. All of these factors could very well influence climate attitudes in the isolation of a survey experiment, but this does not mean they are meaningful drivers of the dynamics of American climate skepticism. We believe scholars need to also examine over time dynamics in the news media environment to examine this question, which has been neglected thus far in research.

This paper situates climate change polarization in the larger literature on citizen cue-taking, opinion formation and persuasion. We argue that out-group cues from Democratic elites caused attitudinal backlash among Republican voters, reflected in their growing embrace of climate skepticism. The role of out-group cues in repelling partisan citizens has been less prominent in literature largely focused on persuasion by in-group elites (Cohen 2003; Kam 2005; Mondak 1993), though the importance of out-group elites have recently come to scholarly attention in the United States (Goren et al. 2009; Nicholson 2012). Our study provides more evidence of the central importance of out-group cues on a pressing and important national issue by marshaling a unique combination of text analysis, time series modeling, and experiments.

We find that the most consistent factor that predicts aggregate patterns of climate skepticism in the public, and among Republican supporters specifically, are cues from Democratic party elites. We find that Democratic elite cues lead rather than follow public opinion on this topic (H1) and that they are contemporaneously correlated with public opinion even after controlling for other factors scholars have deemed important in shaping attitudes towards climate change (H2).

These findings are supported by our survey experiment. We find that polarizing party cues from Democratic (and Republican) elites increase climate skepticism among Republican Party supporters (H3). We found this to be the case with thin treatments and after decades of partisan polarization has already occurred. We did not find a consistently similar effect among Democratic Party supporters, though we must sound a word of caution on this latter point. It is possible these results were hampered by a ceiling effect - Democratic supporters are already very supportive of the climate change consensus, so it is possible our treatments could not move the needle any further. The backlash exhibited by Republican respondents to Democratic elite cues rivals the persuasive 
power of in-group cues from Republican elites in our sample, but it also appears to be attenuated by consensus cues signaling agreement between Democratic and Republican elites on climate science and the need for mitigation.

In short, we show that the story behind climate change polarization is similar to other political issues of the day: members of the public were exposed to a large volume of partisan messages on climate change as the issue grew in salience - in this case primarily from Democratic elites - and formed their opinions accordingly. This work joins an emerging literature on the role of the media and elite cues in climate change polarization (Carmichael and Brulle 2017; Guber 2013; Merkley and Stecula 2018; Tesler 2017), work showing the persuasive influence of out-group party cues (Berinsky 2009; Bischof and Wagner 2019; Feddersen and Adams 2018; Goren et al. 2009; Nicholson 2012).

There are a number of important implications from these findings. First, party elites who strongly identify with the scientific consensus on climate change or other issues must weigh the costs and benefits of aggressively communicating their stance in the mass media. The rising prevalence of party elites in news coverage of climate change was inevitable at some level because of the need for large-scale policy action, but this finding has implications for other scientific issues, such as the safety of genetically modified organisms (GMOs) and vaccines. Efforts to bring these issues into the realm of elite conflict will almost surely lead to polarization as an unanticipated consequence.

Second, emphases on ideology and motivated cognition, while important to understanding why persuading Republicans and conservatives about the perils of climate change is a tough task at present, is perhaps of more limited utility in helping us explain how we got to this point in the first place. Republican supporters were not always so skeptical of climate change. They listened to, and formed opinions based on, signals from trusted opinion leaders within their communities. By viewing the roots of climate change skepticism primarily in deep-seated ideological and value constructs, we minimize the degree to which elites can shape those constructs. It also means that these elites can turn the tide by taking climate change out of the realm of hyper-partisan conflict. Although our experiment did not find a de-polarizing effect of a consensus cue treatment, a stronger treatment featuring highly respected Republican officials may have more success.

Lastly, and relatedly, the potentially prominent role of party elites in the formation of public attitudes on climate change suggests scholars should invest less time and resources in identifying messaging strategies to mobilize support for the climate consensus, and more on understanding the motivations and behavior of party elites. Finding ways to mobilize an elite consensus across partisan 
lines is perhaps the most promising strategy to bring public opinion alongside the scientific consensus on climate change.

\section{References}

Achen CH and Bartels LM (2016) Democracy for Realists: Why Elections Do Not Produce Responsive Government. Princeton, NJ: Princeton University Press

Althaus SL, Edy JA, Entman RM and Phalen P (1996) Revising the Indexing Hypothesis: Officials, Media, and the Libya Crisis. Political Communication 13, 407-421.

Amdur D, Rabe BG and Borick C (2014) Public Viens on a Carbon Tax Depend on the Proposed Use of Revenue: A Report From The National Surveys On Energy And Environment. Issues in Energy and Environmental Policy, no. 13. Center for Local, State and Urban Policy, University of Michigan. Retrieved from http://closup.umich.edu/files/ieep-nsee-2014-spring-carbontax.pdf

Ansolabehere S and Konisky DM (2014) Cheap and Clean. How Americans Think about Energy in the Age of Global Warming. Boston, MA: MIT Press.

Barber M and Pope CC (2019) Does Party Trump Ideology? Disentangling Party and Ideology in America. American Political Science Review 113(1): 38-54.

Bechtel MM and Scheve KF (2013) Mass Support for Global Climate Agreements Depends on Institutional Design. Proceedings of the National Academy of Sciences 110(34): 13763-13768.

Bennett WL (1990) Toward a Theory of Press-State Relations. Journal of Communication 40(2): 103125.

Berinsky AJ (2009) In Time of War: Understanding American Public Opinion from World War II to Iraq. Chicago: University of Chicago Press.

Bischof D and Wagner M (2019) Do Voters Polarize When Extreme Parties Enter Parliament? American Journal of Political Science 63(4): 888-904.

Boykoff MT and Boykoff JM (2007) Climate Change and Journalistic Norms: A Case-Study of US Mass-Media Coverage. Geoforum 38(6): 1190-1204.

Brulle RJ, Carmichael J and Jenkins JC (2012) Shifting Public Opinion on Climate Change: An Empirical Assessment of Factors Influencing Concern over Climate Change in the U.S., 20022010. Climatic Change 114, 169-88.

Campbell TH and Kay AC (2014) Solution Aversion: On the Relation between Ideology and Motivated Disbelief. Journal of Personality and Social Psychology 107(5): 809-824. 
Carmichael JT and Brulle RJ (2017) Elite Cues, Media Coverage, and Public Concern: An Integrated Path Analysis of Public Opinion on Climate Change, 2001-2013. Environmental Politics 26, 232-252.

Carmichael JT, Brulle RJ and Huxter J (2017) The Great Divide: Understanding the Role of Media and Other Drivers of the Partisan Divide in Public Concern over Climate Change in the USA, 2001-2014. Climatic Change 141, 599-612

Cohen GL (2003) Party over Policy: The Dominating Impact of Group Influence on Political Beliefs. Journal of Personality and Social Psychology 85(5): 808-822.

Conover PJ and Feldman S (1989) Candidate Perception in an Ambiguous World: Campaigns, Cues, and Inference Processes. American Journal of Political Science 33(4): 912-940.

Corbett JB and Durfee JL (2004) Testing Public (Un)Certainty of Science: Media Representations of Global Warming. Science Communication 26(2): 129-151.

Dalton RJ, Beck PA and Huckfeldt R (1998) Partisan Cues and the Media: Information Flows in the 1992 Presidential Election. American Political Science Review 92(1): 111-126.

Davis JJ (1995) The Effects of Message Framing on Response to Environmental Communications. Journalism \& Mass Communication Quarterly 72(2): 285-299.

Ditto PH and Lopez DF (1992) Motivated Skepticism: Use of Differential Decision Criteria for Preferred and Non-Preferred Conclusions. Journal of Personality and Social Psychology 63(4): 568584.

Dixon G, Hmielowski J and Ma Y (2017) Improving Climate Change Acceptance among U.S. Conservatives through Value-Based Message Targeting. Science Communication 39(4): 520-534.

Druckman JN (2005) Media Matter: How Newspapers and Television News Cover Campaigns and Influence Voters. Political Communication 22(4): 463-481.

Drutman L (2017) Political Divisions in 2016 and Beyond: Tensions Between and Within the Two Parties. Report from the Democracy Fund Voter Study Group. Retrieved from https://www.voterstudygroup.org/publications/2016-elections/political-divisions-in-2016and-beyond

Dunlap RE and Jacques PJ (2013) Climate Change Denial Books and Conservative Think Tanks: Exploring the Connection. American Behavioral Scientist 57(6): 699-731.

Dunlap RE and McCright AM (2011) Organized Climate Change Denial. In Dryzek JS, Norgaard RB and Schlosberg D (eds), The Oxford Handbook of Climate Change and Society. Oxford: Oxford University Press. 
Elliott E, Seldon BJ and Regens JL (1997) Political and Economic Determinants of Individuals Support for Environmental Spending. Journal of Environmental Management 51(1): 15-27.

Erikson RS, Mackuen MB and Stimson JA (2002) Macro Polity. Cambridge: Cambridge University Press.

Eyck TAT and Williment M (2003) The National Media and Things Genetic: Coverage in the New York Times (1971-2001) and the Washington Post (1977-2001). Science Communication 25(2): 129-152.

Farnsworth SJ and Lichter SR (2005) The Mediated Congress: Coverage of Capitol Hill in the New York Times and the Washington Post. Harvard International Journal of Press/Politics 10(2): 94-107.

Farrell J (2016a) Corporate Funding and Ideological Polarization about Climate Change. Proceedings of the National Academy of Sciences 113(1): 92-97.

Farrell J (2016b) Network Structure and Influence of the Climate Change Counter-Movement. Nature Climate Change 6, 370-74.

Feddersen A and Adams J (2018) Public Opinion Backlash in Response to Party Press Releases: Evidence from the (Unlikely) Swiss Case. Paper presented at the Annual Meeting of the American Political Science Association, Boston.

Feygina I, Jost JT and Goldsmith RE (2010) System Justification, the Denial of Global Warming, and the Possibility of 'System-Sanctioned Change.' Personality and Social Psychology Bulletin 36(3): $326-338$.

Friedman SM, Dunwoody S and Rogers CL (eds) (1999) Communicating Uncertainty: Media Coverage of New and Controversial Science, 1 st edition. Mahwah, N.J: Routledge.

Golan G (2006) Inter-media Agenda Setting and Global News Coverage: Assessing the Influence of the New York Times on Three Network Television Evening News Programs. Journalism Studies 7(2): 323-333.

Goren P, Federico CM and Kittilson MC (2009) Source Cues, Partisan Identities, and Political Value Expression. American Journal of Political Science 53(4): 805-820.

Grimmer J and Stewart BM (2013) Text as Data: The Promise and Pitfalls of Automatic Content Analysis Methods for Political Texts. Political Analysis 21(3): 267-297.

Guber DL (2013) A Cooling Climate for Change? Party Polarization and the Politics of Global Warming. American Behavioral Scientist 57, 93-115. 
Iyengar S, Sood G and Lelkes Y (2012) Affect, not Ideology: A Social Identity Perspective on Polarization. Public Opinion Quarterly 76, 405-431.

Jacques PJ, Dunlap RE and Freeman M (2008) The Organisation of Denial: Conservative Think Tanks and Environmental Scepticism. Environmental Politics 17(3): 349-385.

Kahan DM, Jenkins-Smith H and Braman D (2011) Cultural Cognition of Scientific Consensus. Journal of Risk Research 14(2): 147-174.

Kam C (2005) Who Toes the Party Line? Cues, Values, and Individual Differences. Political Behavior 27(2): 163-182.

Kinder DR and Kalmoe NP (2017) Neither Liberal nor Conservative: Ideological Innocence in the American Public. Chicago, IL: University of Chicago Press

Koehler DJ (2016) Can Journalistic 'False Balance' Distort Public Perception of Consensus in Expert Opinion? Journal of Experimental Psychology: Applied 22(1): 24-38.

Krosnick JA, Holbrook AL and Visser PS (2000) The Impact of the Fall 1997 Debate about Global Warming on American Public Opinion. Public Understanding of Science 9, 239-60.

Kunda Z (1990) The Case for Motivated Reasoning. Psychological Bulletin 108(3): 480-498.

Lacy S, Watson BR, Riffe D and Lovejoy J (2015) Issues and Best Practices in Content Analysis. Journalism \& Mass Communication Quarterly 92(4): 791-811.

Leiserowitz A (2006) Climate Change Risk Perception and Policy Preferences: The Role of Affect, Imagery, and Values. Climactic Change 77(1/2): 45-72.

Lenz GS (2012) Follow the Leader? How Voters Respond to Politicians' Policies and Performance. Chicago: University of Chicago Press.

Lewandowsky S and Oberauer K (2016) Motivated Rejection of Science. Current Directions in Psychological Science 25(4): 217-222.

Lodge M and Taber CS (2013) The Rationalizing Voter. Cambridge: Cambridge University Press.

McCombs ME (2005) A look at Agenda-Setting: Past, Present and Future. Journalism Studies 6, 543557.

Merkley E and Stecula DA (2018) Party Elites or Manufactured Doubt? The Informational Context of Climate Change Polarization. Science Communication 40(2): 258-274.

Nicholson SP (2012) Polarizing Cues. American Journal of Political Science 56(1): 52-66.

Nisbet MC (2009) Communicating Climate Change: Why Frames Matter for Public Engagement. Environment: Science and Policy for Sustainable Development 51(2): 12-23. 
Oreskes N and Conway EM (2010) Merchants of Doubt: How a Handful of Scientists Obscured the Truth on Issues from Tobacco Smoke to Global Warming. New York: Bloomsbury Press.

Painter J (2013) Climate Change in the Media: Reporting Riske and Uncertainty. I.B.Tauris.

Painter J and Ashe T (2012) Cross-national Comparison of the Presence of Climate Scepticism in the Print Media in Six Countries, 2007-10. Environmental Research Letters 7(4): 044005.

Pasek J (2017) "It's Not My Consensus: Motivated Reasoning and the Sources of Scientific Illiteracy." Public Understanding of Science 27(7): 787-806.

Popkin SL (1991) The Reasoning Voter: Communication and Persuasion in Presidential Campaigns. Chicago: University of Chicago Press.

Scruggs L and Benegal S (2012) Declining Public Concern about Climate Change: Can We Blame the Great Recession? Global Environmental Change 22, 505-15.

Soroka SN, Stecula DA and Wlezien C (2015) It's (Change in) the (Future) Economy, Stupid: Economic Indicators, the Media, and Public Opinion. American Journal of Political Science 59(2): 457-474.

Stecula DA and Merkley E (2019) Framing Climate Change: Economics, Ideology, and Uncertainty in American News Media Content from 1988 to 2014. Frontiers in Communication 4 doi:10.3389/fcomm.2019.00006

Stimson JA (1999) Public Opinion in America: Moods, Cycles, and Swings. Boulder, CO: Westview Press.

Tesler M (2017) Elite Domination of Public Doubts about Climate Change (Not Evolution). Political Communication 35(2): 306-326.

Varo CJ and Guo L (2017) Networks, Big Data, and Intermedia Agenda Setting: An Analysis of Traditional, Partisan, and Emerging Online U.S. News. Journalism \& Mass Communication Quarterly 94(4): 1031-1055.

Vries GD, Terwel BW and Ellemers N (2016) Perceptions of Manipulation and Judgments of Illegitimacy: Pitfalls in the Use of Emphasis Framing when Communicating about $\mathrm{CO} 2$ Capture and Storage. Environmental Communication 10(2): 206-226.

Winter NJG, Burleigh T, Kennedy R and Clifford S (2019) A Simplified Protocol to Screen out VPS and International Respondents Using Qualtrics. Available at SSRN: https: / / ssrn.com/abstract $=3327274$.

Zaller J (1992) The Nature and Origins of Mass Opinion. New York: Cambridge University Press. 